\title{
DETERMINAN KINERJA PERAWAT DALAM PENERAPAN PATIENT SAFETY DI RS IMELDA PEKERJA INDONESIA TAHUN 2020
}

\author{
Puput Melati Hutauruk ${ }^{1}$, Rahmawani Fauza ${ }^{2}$ \\ ${ }^{I}$ Program Studi D-IV Manajemen Informasi Kesehatan, Universitas Imelda Medan \\ ${ }^{2}$ Program Studi S1 Kebidanan, Universitas Imelda Medan \\ Email: ${ }^{1}$ puputmelati.pm71@gmail.com, ${ }^{2}$ rahmawani.29@gmail.com
}

\begin{abstract}
ABSTRAK
Kinerja perawat merupakan bagian integral dalam pelayanan kesehatan. Fakor-faktor yang mempengaruhi kinerja perawat turut berperan dalam keefektifan penerapan patient safety dalam asuhan keperawatan, diantaranya adalah faktor motivasi perawat, dan beban kerja perawat. Motivasi kerja perawat akan dapat mempengaruhi pelaksanaan patient safety. Beban kerja perawat juga dapat memberi efek keoptimalan dalam pemberian asuhan pelayanan. Tujuan penelitian ini adalah untuk mengetahui determinan kinerja perawat dalam penerapan patient safety di RS Imelda Pekerja Indonesia. Metode penelitian kuantitatif dengan cross sectional study. Populasi penelitian meliputi seluruh perawat ruang rawat inap RS Imelda Medan sejumlah 217 orang, dengan sampel sebanyak 140 orang sesuai dengan kriteria inklusi yang ditentukan. Analisis data menggunakan distribusi frekuensi dan uji chi square. Hasil penelitian diperoleh bahwa ada pengaruh motivasi kerja perawat dalam penerapan patient safety di $R S$ Imelda Pekerja Indonesia dengan p-value=0,000 <0.05 dan juga ada pengaruh beban kerja perawat dalam penerapan patient safety di RS Imelda Pekerja Indonesia dengan nilai $p$-value=0,000<0.05. Sehubungan dengan upaya meningkatkan kinerja perawat di RS Imelda Pekerja Indonesia, maka kepala perawatan harus lebih memperhatikan hal-hal yang berkaitan dengan pemberian motivasi serta aturan mengenai beban kerja perawat agar perawat dapat memaksimalkan kinerjanya.
\end{abstract}

Kata kunci : Motivasi, Beban Kerja, Kinerja Perawat, Patient Safety.

\section{ABSTRACT}

Nurse performance is an integral part of the health service. Factors that influence the performance of nurses play a role in the effectiveness of the application of patient safety in nursing care, including the motivational factors of nurses, and the workload of nurses. The motivation of the nurse's work will be able to influence the implementation of patient safety. Nurse workloads can also have an optimal effect on the provision of care services.The purpose of this study was to determine the determinant of nurse performance in the application of patient safety at Imelda Pekerja Indonesia Hospital. Quantitative research method with cross sectional study. The study population includes all inpatient room nurses of Imelda Medan Hospital which amounts to 217 people, with a sample of 140 people in accordance with the specified inclusion criteria. Data analysis using frequency distribution and chi square test. The results of the study were obtained that there is an influence of nurse work motivation in the application of patient safety in Imelda Pekerja Indonesia Hospital with p-value $=0.000<0.05$ and there is also the influence of nurse workload in the application of patient safety in Imelda Pekerja Indonesia Hospital with a value of $p$-value $=0.000<0.05$. In connection with efforts to improve the performance of nurses in the application of patient safety at Imelda Pekerja Indonesia Hospital, the head of care must pay more attention to matters related to providing motivation and rules regarding nurse workload so that nurses can maximize their performance.

Keywords: Motivation, Workload, Nurse Performance, Patient Safety.

\section{PENDAHULUAN}

Keselamatan pasien merupakan isu global yang paling penting saat ini, dimana banyak dilaporkan tuntutan pasien atau medication error. Pelayanan kesehatan yang diberikan pada rumah sakit sangat memungkinkan terjadinya kesalahan. Dengan memastikan pasien memperoleh hak-haknya, yakni mendapatkan pelayanan keperawatan yang aman adalah merupakan tujuan pemberian layanan keperawatan pada pasien. Oleh karena itu, adanya sistem yang aman sangat diperlukan untuk menghindari terjadinya miss data dalam pelaksanaan 
teknologi kesehatan rumah sakit, karena rumah sakit sebagai penyedia fasilitas kesehatan yang memiliki sumber daya kesehatan dalam mendukung penyelenggaraan program keselamatan pasien (Depkes, 2008).

Hospital Patient Safety adalah sistem yang dibentuk rumah sakit dalam memberikan asuhan kepada pasien untuk memberikan keamanan pada pasien (Depkes, 2008). Keselamatan pasien menjadi isu penting karena banyaknya kasus medical error yang terjadi di berbagai Negara, yang mengakibatkan pasien meninggal dimana seharusnya $50 \%$ diantaranya dapat dicegah (Handayani, 2012).

Hasil penelitian yang dilakukan pada sebuas RS di Utah dan Colorado serta New York ditemukan kejadian yang tidak diharapkan yang terjadi pada di wilayah Utah dan Colorado sebesar 2,9\%, dan sebanyak 6,6\% diantaranya meninggal dunia.

Emergency Departement (ED) adalah tiga lokasi tertinggi di rumah sakit untuk terjadinya error disamping unit perawatan intensif (ICU) dan kamar operasi. Kondisi kesalahan yang terjadi di ED disebabkan oleh, ketidakpastian diagnostik, tingkat pengetahuan perawat dan umpan balik yang buruk, dan kurangnya kontinuitas perawatan di Emergency Department (ED) (Chan, Huang, \& You, 2012; Paul, Reddy, 2010).

Patient Safety rumah sakit merupakan sistem yang dibuat untuk mencegah terjadinya KTD yang disebabkan ada tidaknya tindakan oleh medis atau nonmedis. Sistem tersebut meliputi: assesment risiko, identifikasi pasien, terjadinya risiko pasien, laporan dan analisa insiden, tindak lanjut atas insiden, dan solusi dalam mengurangi timbulnya risiko (Mawansyah, 2017).

Perawat dalam kinerjanya menjalankan tugas-tugas asuhan keperawatan dengan mengimplenemtasikan patient safety sebagai bagian dari kinerjanya untuk melaksanakan asuhan keperawatan. Implementasi Patient Safety merupakan tindakan yang dilakukan untuk mengurangi kemungkinan terjadinya efek samping dari perawatan kesehatan yang diberikan. Perawat yang memberikan perawatan berperan penting menjaga keselamatan pasien dengan mengawasi kondisi pasien agar tidak terjadi insiden, kesalahan maupun cedera, memberikan pemahaman perawatan kesehatan dan memastikan pasien menerima perawatan yang memuaskan (Effken \& Abbott, 2009; "Nursing the Demands Of Quality, Patient Care," 2008). Aktifitas keperawatan dalam melaksanakan keselamatan pasien seperti cuci tangan, identifikasi pasien, keamanan obat, dan komunikasi yang efektif adalah merupakan bagian dari implementasi keselamatan pasien yang dilakukan perawat sebagai upaya untuk mengurangi KTD selama perawatan di rumah sakit. Namun dalam yang dilakukan ditemukan bahwa beberapa KTD tidak semuanya dapat didokumentasikan pada catatan dan laporan KTD rumah sakit (Abraham, Watson, \& Bcudreau, 2008; "New Grading System For Patient Safety," 2012).

Peran perawat dalam meningkatkan keselamatan pasien juga telah menjadi standar kelima dalam target keselamatan pasien RS di Indonesia. Ada tujuh elemen yang berpengaruh dalam budaya keselamatan pasien, dan komitmen perawat akan keselamatan merupakan elemen pertama yang mempengaruhi budaya keselamatan pasien (Mawansyah, 2017).

Fakor-faktor yang mempengaruhi kinerja perawat turut berperan dalam keefektifan penerapan patient safety dalam asuhan keperawatan, diantaranya adalah faktor motivasi perawat, dan beban kerja perawat. Dalam penelitian Mawansyah, perawat dengan prestasi kerja tinggi disebabkan adanya motivasi yang tinggi, sebaliknya perawat dengan motivasi rendah mengakibatkan prestasi kerjanya rendah dan hal ini dapat mempengaruhi pelaksanaan patient safety (Mawansyah, 2017). Sedangkan, kelelahan kerja perawat memberi dampak kurang optimalnya pemberian asuhan pelayanan. Beban kerja yang inggi dapat mengakibatkan penurunan kinerja pada personel rumah sakit (Nursalam, 2011)

Sesuai dengan hasil laporan pencatatan patient safety tahun 2017 tercatat bahwa ada beberapa kejadian tidak diinginkan di Rumah Sakit Imelda Pekerja Indonesia Medan, sehubungan dengan tindakan asuhan keperawatan yang diberikan seperti: kesalahan diagnosis yang pada akhirnya menyebabkan kesalahan dalam pemberian obat, keterlambatan diagnosis yang menyebabkan pasien mengalami 
keterlambatan penanganan, dan kejadian yang tidak diinginkan lainnya. Perawat merupakan komponen sumber daya manusia yang penting dalam sistem pelayanan kesehatan di RS Imelda Pekerja Indonesia yang bertugas langsung dan berhadapan langsung dengan pasien. Mengingat pentingnya peran perawat, maka perawat dituntut aktif berpartisipasi dalam mengimplementasikan keselamatan pasien di rumah sakit. Maka dari itu, berdasarkan data awal tersebut dapat dijadikan data awal untuk dilakukan penelitian lebih lanjut.

\section{METODE}

Jenis penelitian yang dipakai oleh peneliti sebagai pendekatan dalam penelitian adalah kuantitatif. Desain penelitian menggunakan studi potong lintang (cross sectional study), yang bertujuan mempelajari pengaruh antara variabel independen/bebas (beban kerja dan motivasi kerja) dengan variabel dependen/terikat (penerapan patient safety) diteliti sekaligus pada saat yang sama.

Populasi dalam penelitian berjumlah 217 terdiri dari perawat ruang rawat inap RS.IPI, dengan jumlah sampel 140 orang (teknik total sampling), sesuai dengan inklusi yang telah ditetapkan, yaitu perawat bersedia sebagai responden, perawat yang bertugas di ruangan rawat inap dan perawat yang tidak sedang menjalani cuti.

Sumber data berasal dari kuesioner yang telah diisi oleh responden dan data yang di dapatkan dari kepala kepegawaian yaitu untuk mengetahui jumlah perawat pelaksana di RS Imelda Medan. Analisa data menggunkan distribusi frekuensi yang menggambarkan secara tunggal variabelvariabel penelitian baik independen (motivasi kerja, dan beban kerja) maupun variabel dependen/terikat (Penerapan Patient Safety) dan uji chi-squre untuk melihat hubungan variabel independen (motivasi kerja, dan beban kerja) dengan variabel dependen/terikat (Penerapan Patient Safety).
3. HASIL DAN PEMBAHASAN

3.1 Hasil Penelitian

Karakteristik Responden

Tabel 1. Distribusi Frekuensi Karakteristik Responden

\begin{tabular}{|c|c|c|c|}
\hline No & Karakteririk Responden & $\mathbf{F}$ & $(\%)$ \\
\hline \multirow[t]{5}{*}{1} & Usia : & & \\
\hline & $20-29$ Tahun & 73 & 52,15 \\
\hline & $30-39$ Tahun & 39 & 27,85 \\
\hline & $\geq 40$ Tahun & 28 & 20,00 \\
\hline & Total & 140 & 100,00 \\
\hline \multirow[t]{4}{*}{2} & Masa Kerja : & & \\
\hline & Kurang dari 5 tahun & 67 & 47.86 \\
\hline & Lebih dari 5 tahun & 73 & 52.14 \\
\hline & Total & 140 & 100,00 \\
\hline \multicolumn{4}{|c|}{3 Tingkat Pendidikan } \\
\hline & DIII & 75 & 53,57 \\
\hline & S1 & 35 & 25,00 \\
\hline & Profesi (Ners) & 30 & 21,43 \\
\hline & Total & 140 & 100,00 \\
\hline \multicolumn{4}{|c|}{$\begin{array}{l}\text { Berdasarkan data distribusi frekuensi } \\
\text { pada Tabel } 1 \text { menunjukkan distribusi usia } \\
\text { responden. Untuk proporsi usia terbesar } \\
\text { adalah usia } 20-29 \text { tahun }(52,15 \%) \text {, diikuti } \\
\text { usia } 30-39 \text { tahun }(27,85 \%) \text {, dan yang terkecil } \\
\text { usia } \geq 40 \text { tahun }(14 \%) \text {. Hal ini dapat dijadikan } \\
\text { gambaran bahwa produktivitas tenaga kerja, } \\
\text { menurut BPS usia produktif dimulai dari usia } \\
15-64 \text { tahun, maka distribusi tenaga perawat } \\
\text { yang ada termasuk dalam kategori tenaga } \\
\text { produktif. }\end{array}$} \\
\hline
\end{tabular}

Sedangkan pada distribusi masa kerja menunjukkan bahwa sebagian besar yaitu $52,14 \%$ responden memiliki masa kerja lebih dari 5 tahun dan sebagian lainnya yaitu 47,86\% kurang dari 5 tahun. Hal tersebut menunjukkan bahwa responden telah cukup lama menjalankan profesinya sebagai perawat, dengan semakin lama seseorang bekerja maka akan semakin banyak pengalaman yang dimilikinya khususnya dalam menghadapi kasus yang ditanganinya karena banyaknya pengalaman bekerja yang dimiliki akan banyak memberikan keahlian dan keterampilan dalam bekerja.

Karakteristik responden berdasarkan distribusi tingkat pendidikan menunjukkan kebanyakan responden berpendidikan DIII $(53,57 \%)$, kemudian yang berpendidikan S1 sebanyak 35 orang (25\%) dan selebihnya 30 responden berpendidikan Profesi (Ners) sebanyak 30 orang $(21,43 \%)$. Perawat yang 
profesional harus memiliki latar belakang pendidikian keperawatan minimal DIII Keperawatan yang bertujuan agar perawat mampu melaksanakan asuhan keperawatan dengan pendekatan proses keperawatan, taat pada kode etik, memiliki kemampuan komunikasi yang baik dengan pasien dan keluarga, mampu memanfaatkan sarana kesehatan, mampu berperan sebagai agen pembaharu dan mengembangkan ilmu serta teknologi keperawatan.

\section{Hasil Uji Variabel}

Tabel 2. Hasil Crosstab Motivasi Kerja dan Beban Kerja dengan Kinerja Perawat

\begin{tabular}{|c|c|c|c|c|c|c|}
\hline & & \multicolumn{2}{|c|}{ Kinerja Perawat } & \multirow{2}{*}{ Total } & \multirow{2}{*}{$\%$} & \multirow{2}{*}{$P$-value } \\
\hline & & Kurang Baik & Baik & & & \\
\hline \multirow{2}{*}{$\begin{array}{l}\text { Motivasi } \\
\text { Kerja }\end{array}$} & Rendah & 25 & 0 & 25 & 17,86 & \multirow{2}{*}{0,000} \\
\hline & Tinggi & 22 & 93 & 115 & 82,14 & \\
\hline \multicolumn{2}{|c|}{ Total } & 47 & 93 & 140 & 100 & \\
\hline \multirow{2}{*}{ Beban Kerja } & Berat & 38 & 37 & 75 & 53,57 & \multirow{2}{*}{0.000} \\
\hline & Ringan & 9 & 56 & 65 & 46,43 & \\
\hline \multicolumn{2}{|c|}{ Total } & 47 & 93 & 140 & 100 & \\
\hline
\end{tabular}

Berdasarkan tabel 2 diperoleh data distribusi frekuensi masing-masing variabel, bahwa mayoritas motivasi kerja responden tinggi sebanyak 115 orang $(82,14 \%)$, beban kerja mayoritas responden berat sebanyak 75 orang $(53,57 \%)$, dengan kinerja perawat mayorita sperawat baik sebanyak 93 orang $(66,43 \%)$.

Hasil uji crosstab pada variabel motivasi kerja diketahui bahwa dari 115 orang responden dengan motivasi kerja tinggi terdapat 93 orang responden yang kinerjanya baik dan sisanya sebanyak 22 orang responden memiliki kinerja yang kurang baik. Sedangkan dari 25 responden memiliki motivasi kerja rendah keseluruhannya memiliki kinerja yang kurang baik. Pada hasil uji chi square juga diketahui bahwa nilai pvalue $=0,000<0,050$, yang berarti bahwa terdapat pengaruh motivasi kerja dengan kinerja perawat dalam penerapan keselamatan pasien di RS Imelda Pekerja Indonesia.

Kemudian pada hasil uji crosstab pada variabel beban kerja diperoleh bahwa dari 65 responden memiliki beban kerja ringan terdapat 56 orang responden dengan kinerja yang baik dan sisanya sebanyak 9 orang responden dengan kinerja yang kurang baik. Sedangkan dari 75 responden memiliki beban kerja berat, terdapat 37 orang responden memiliki kinerja baik dan 38 orang responden dengan kinerja kurang baik. Hasil uji chisquare juga menunjukkan bahwa nilai $\mathrm{p}$-value $=0,000<0,050$, yang berarti bahwa terdapat pengaruh beban kerja dengan kinerja perawat dalam penerapan keselamatan pasien di RS Imelda Pekerja Indonesia.

\subsection{Pembahasan}

\section{Pengaruh Motivasi Kerja Perawat \\ Terhadap Kinerja Perawat Dalam Penerapan Patient Safety di RS Imelda Pekerja Indonesia}

Hasil penelitian didapatkan bahwa motivasi kerja perawat memiliki nilai signifikan sebesar 0,000, yang berarti lebih kecil dari nilai signifikansinya yaitu 0,05 . Dengan demikian dapat disimpulkan bahwa motivasi kerja memiliki pengaruh yang signifikan terhadap kinerja perawat. Motivasi kerja berhubungan dengan kinerja atau prestasi kerja karena apabila motivasi kerja seseorang rendah maka kinerjanya pun akan tidak optimal. Motivasi kerja berkaitan dengan kemauan atau dorongan seseorang untu melakukan pekerjaan. Aspek motivasi kerja seseorang terkait erat dengan kebutuhan yang mendasari seseorang untuk bekerja seperti kebutuhan akan berprestasi (kinerja), penghargaan, rasa tanggung jawab, keinginan untuk tumbuh dan berkembang dan pekerjaan itu sendiri.

Penelitian yang dilakukan oleh Tjahjono dan Gunarsih menunjukkan bahwa variabel motivasi secara individual berpengaruh secara signifikan terhadap kinerja pegawai (Tjahjono dan Gunarsih, 2008). Sihotang 
dalam penelitiannya tentang hubungan motivasi dengan kinerja perawat di Rumah Sakit Umum Doloksanggul dalam memberikan pelayanan kepada pasien menunjukkan adanya hubungan yang signifikan antara morivasi dengan kinerja perawat di rumah sakit tersebut (Sihotang, 2006).

Berdasarkan data pada tabel 2 diketahui bahwa sebagian besar perawat memiliki motivasi dengan kategori baik, sehingga dengan motivasi yang baik akan meningkatkan kinerja perawat. Hal ini sesuai dengan penelitian Badi'ah yang menunjukkan bahwa ada hubungan yang signifikan antara faktor motivasi internal dan faktor motivasi eksternal dengan kinerja perawat (Badi'ah, 2008).

Pada penelitian ini, motivasi kerja perawat diberikan melalui pemberian gaji, promosi jabatan, pelatihan, pengakuan, supervisi, tim kerja, kenyamanan kerja, lingkungan kerja dan tanggung jawab. Motivasi merupakan dorongan, rangsangan, yang dimiliki pada perilakunya untuk berbuat dan bekerja secara optimal melaksanakan untuk mencapai tujuan yang telah ditetapkan. Motivasi kerja perawat meliputi keadaan yang mempengaruhi perilakunya dalam lingkungan kerja. Berdasarkan hasil penelitian diperoleh bahwa mayoritas perawat termotivasi $(75 \%)$ untuk bekerja lebih baik adalah karena adanya imbalan gaji yang sesuai, ketepatan waktu dalam penerimaan gaji dan adanya kenaikan gaji setiap tahun, dan pemberian pelatihan. Selain itu, sebagian besar perawat mengatakan kurang termotivasi pada indikator pengakuan (73\%), dimana perawat jarang mendapatkan pengakuan berupa penghargaan atau reward terhadap prestasi kerja mereka dari atasan, sehingga hal tersebut menyebabkan perawat dalam memberikan pelayanan keperawatan tidak maksimal.

Motivasi kerja perawat dibutuhkan dalam melakukan penerapan patient safety agar dapat memberikan kinerja yang baik dalama memberikan layanan asuhan keperawatan, juga dalam penerapan patient safety. Oleh karena itu, perawat di RS Imelda Pekerja Indonesia diberikan pelatihan sebagai bentuk motivasi untuk meningkatkan kinerja perawat. Pelatihan memotivasi perawat dalam memberikan pelayanan yang lebih berkualitas, dimana selain bertambahnya pengetahuan dan kemampuan perawat dalam melaksanakan asuhan keperawatannya, perawat yang telah mengikuti pelatihan juga diberikan tambahan kenaikan gaji yang nominalnya telah ditentukan oleh manajemen rumah sakit. Selain kenaikan gaji. perawat yang mengikuti pelatihan juga adakalanya diberikan kenaikan jabatan dimana umumnya kenaikan jabatan yang diberikan berupa menjadi kepala ruangan atau dipindahkan ke unit layanan yang dibuka sesuai kebutuhan rumah sakit. Kondisi demikian tentunya akan meningkatkan motivasi perawat dalam meningkatkan kinerjanya.

Hasil distribusi frekuensi diketahui bahwa sebanyak $82,14 \%$ perawat memiliki motivasi kerja yang tinggi. Perawat dengan motivasi kerja tinggi tentunya akan mendukung penerapan program patient safety dengan berpartisipasi aktif dalam mewujudkan keselamatan pasien rumah sakit. Dengan demikian pemberian gaji, promosi jabatan, dan pelatihan sebagai bentuk motivasi kerja yang diberikan manajemen rumah sakit sangat berperan besar dalam peningkatan kinerja perawat dalam penerapan patient safety di RS Imelda Pekerja Indonesia sehingga memotivasi perawat dalam meningkatkan pelayanan kepada pasien khususnya dalam menjaga keselamatan pasien.

\section{Pengaruh Beban Kerja Perawat Terhadap Kinerja Perawat Dalam Penerapan Patient Safety di RS Imelda Pekerja Indonesia}

Beban kerja merupakan faktor ekstrinsik individu yang menjadi salah satu sumber munculnya permasalahan kinerja, karena beban kerja yang dihadapinya terlalu tinggi, dimana tidak semua karyawan memiliki tingkat ketahanan terhadap tekanan dari beban kerja yang sama. Menurut Setyawan dan Kuswati bahwa kinerja karyawan akan menurun jika beban kerja yang diberikan tidak sesuai dengan pembagian beban kerjanya (Setyawan dan Kuswati, 2006).

Berdasarkan hasil analisis beban kerja memiliki nilai signifikan sebesar 0,000 yang lebih kecil dari 0,05. Maka dapat disimpulkan bahwa beban kerja memiliki pengaruh yang signifikan terhadap kinerja perawat. Keadaan perawat yang memiliki beban berat ini malah 
memotivasi dirinya untuk dapat mengatasi semua masalah-masalah yang ada dan perawat terus berupaya untuk memaksimalkan kinerjanya. Hal inilah yang menyebabkan terdapat hubungan yang positif antara beban kerja dengan kinerja perawat di Rumah Sakit Sari Mutiara. Hasil ini sejalan dengan hasil penelitian yang dilakukan oleh Artadi yang menyatakan bahwa beban kerja secara individual berpengaruh signifikan terhadap kinerja karyawan (Artadi, 2015).

Hasil penelitian ini menunjukkan bahwa beban kerja perawat yang berat menyebabkan 38 orang perawat dengan kinerja kurang baik dalam penerapan patient safety. Beban kerja yang berbeda di Instalasi Rawat Inap RS Imelda Pekerja Indonesia disebabkan perbedaan aktivitas pada shift kerja, jumlah perawat, jumlah pasien, serta kelas perawatan. Dengan adanya pelaksanaan patient safety maka secara otomatis menambah tugas perawat untuk menjaga pasien tetap selamat. Penambahan beban kerja akan mempengaruhi daya tahan tubuh perawat, karena tidak selamanya daya tahan tubuh manusia akan selalu bertahan, dan pasti akan terjadi penurunan daya tahan tubuh. Penambahan beban kerja yang berlebihan kemungkinan besar dapat menyebabkan gangguan emosional berupa mudah marah, gangguan pencernaan, sakit kepala, lupa dan kelalaian, serta menimbulkan kelelahan baik fisik maupun mental yang berpotensi membahayakan kesehatan pekerja atau perawat (Dwi Retnaningsih, 2016).

Dalam mengantisipasi kondisi demikian, RS Imelda Pekerja Indonesia telah memiliki kebijakan yang mengatur mengenai jam shift kerja perawat yang disesuikan dengan jumlah pasien yang dirawatnya yang bertujuan untuk menghindari terjadinya kejadian yang tidak diharapkan pada keselamatan pasien akibat dari tingginya beban kerja perawat karena terbatasnya perawat.

\section{KESIMPULAN}

1. Ada pengaruh motivasi kerja perawat dalam penerapan patient safety di RS Imelda Pekerja Indonesia.

2. Ada pengaruh beban kerja perawat dalam penerapan patient safety di RS Imelda Pekerja Indonesia.

\section{REFERENCES}

Artadi, Febri. 2015. Pengaruh Kepuasan Kerja Dan Beban Kerja Terhadap Kinerja Karyawan pada PT. Merapi Agung Lestari. Jurnal Economica.

Badi'ah. 2008. Hubungan Motivasi Perawat dengan Kinerja Perawat di Ruang Rawat Inap Rumah Sakit Daerah Panembahan Senopati Bantul Tahun 2008. Jurnal Manajemen Pelayanan Kesehatan. 12 : $74-82$

Dwi, Retnaningsih. 2016. Beban Kerja Perawat Terhadap Implementasi Patient Safetydi Ruang Rawat Inap. Jurnal Keperawatan. STIKes Widya Husada Semarang.

Handayani, Meliana. 2012. Determinan Kepatuhan Perawat di Ruang Rawat Inap Rumah Sakit Stella Maris Makassar. Fakultas Kesehatan Masyarakat Universitas Hasanuddin.

Ilyas, Yaslis. 2012. Kinerja, teori, penilaian dan penelitian. Jakarta: Pusat Kajian Ekonomi Kesehatan FKM Universitas Indonesia.

Mangkunegara, Anwar Prabu Mangkunegara. 2011. Evaluasi Kinerja SDM cetakan ke enam. Bandung: Refika Aditama.

Marseno, Rhudy. 2017. Keselamatan Pasien Rumah sakit. Artikel https://marsenorhudy.wordpress.com/20 11/01/07/patient-safetiy-keselamatanpasien-rumah-sakit/

Mawansyah, LM Toni, 2017. Hubungan Pengetahuan Sikap dan Motivasi Kerja Perawat Denganpelaksanaan Patient Safety di Rumah Sakit Santa Anna Kendari 2017, Jurnal Ilmiah Mahasiswa Kesehatan Masyarakat, Vol. 2/No.6/ Mei 2017; ISSN 2502-73H.

Moh. Taufik Gunibala. 2015. Hubungan Pengetahuan dan Skap Perawat Dengan Penerapan Patient Safety di RSUD Prof. D. HI. Aloei Saboe Kota Gorontalo.

Nursalam. 2011. Manajemen Keperawatan. Edisi 3. Jakarta : Salemba Medika.

Parinussa, Annie F. 2011. Pengaruh Kemampuan Dan Motivasi Kerja Terhadap Kinerja Pegawai Pada Sekretariat DPRD Kota Jayapura. Jurnal Ekonomi dan Bisnis.1 (1) : 34 - 62 .

Persatuan Perawat Nasional Indonesia (PPNI). 2014. Profil Perawat Nasional diIndonesia. Jakarta: PPNI. 
Setyawan, A. A., \& Kuswati, R. 2006.

Teknologi Informasi Dan Reposisi

Fungsi Manajemen Sumber Daya

Manusia. Jurnal Manajemen dan Bisnis.

ISSN.1410 -4571. Hal. 109.

Tjahjono, Binawan Nur dan Tri Gunarsih.

2008. Pengaruh Motivasi Kerja Dan

Budaya Organisasi Terhadap Kinerja

Pegawai di Lingkungan Dinas Bina

Marga Propinsi Jawa Tengah, Jurnal.

Triasmoko Denny, DKK. 2014. Pengaruh

Pelatihan Kerja Terhadap Kinerja

Karyawan PT Pos Indonesia (Persero)

Cabang Kota Kediri. Universitas

Brawijaya Jurnal Administrasi Bisnis

$(J A B)$. Vol. 12 No. 1.

World Health Organization. 2004.

International Statistical Classification of

Disease and Related Health Problems

Tenth Revision Volume 2second edition.

Geneva: World Health Organization.

Yusuf, Muhammad. 2011. Penerapan Patient

Safety Di Ruang Rawat Inap Rumah

Sakit Umum Daerah Dr. Zainoel Abidin.

Jurnal Ilmu Keperawatan (2017) 5:1

ISSN: 2338-6371, e-ISSN 2550-018X. 